\title{
A comparison of the musical scales of the ancient Chinese bronze bell ensemble and the modern bamboo flute
}

\author{
RAO YU-AN \\ Academia Sinica, Shanghai, People's Republic of China \\ and University of California, Los Angeles, California \\ EDWARD C. CARTERETTE \\ University of California, Los Angeles, California \\ and \\ WU YU-KUI \\ Nanjing University, Nanjing, People's Republic of China \\ and University of California, Los Angeles, California
}

\begin{abstract}
We compare over a two-octave range the tonal, interval, and scale relationships of an ancient Chinese bell ensemble of the Zhou Dynasty and a modern bamboo flute. By using subjective pitches, a tonal system with simple harmonic partials (the flute) could be compared with a tonal system with complex inharmonic partials (the bell). We argue that the underlying musical scales of the bell ensemble and the flute are closely related and lie between an unequal-interval pure-system scale and the just-intonation scale. There is some evidence that a least interval of 60 or 66 cents figures in the flute scale, that both flute and bell scales include a 90 -cent interval and a true $(1,200$-cent) octave, and that neither scale includes a 100-cent interval. Since there is a true octave, the scales cannot be cycles of fifths, and since there is no equal-temperament half-tone (100 cents), the scales cannot be equal in temperament. We conclude that the flute and Zhou bell scales are very similar if not the same. Apparently, strong cultural traditions and human perceptual constancies united to sustain a common flexible musical scale during 2,400 years.
\end{abstract}

In a paper exploring Chinese musical scales, Pan and Rao (1975) reported on the pure-scale system of 23 tones of unequal intervals that existed in China for a very long time. A pure scale or pure-scale system is defined as one in which the essential intervals are in tune and intonation and modulation is flexible. Pan and Rao verified the scale experimentally, using a stone flute that was made about the Ching (Manchu) ${ }^{1}$ dynasty (A.D. 1644-1911). ${ }^{2}$ Because China is an extensive land containing many nations living together, each with an ancient cultural tradition, its music exhibits a great variety of styles and instruments

This research was supported in part by grants from The Institute of Physiology, Academia Sinica, Shanghai; The Committee on Research of The Academic Senate, UCLA; The Regents of The University of California; and the U.S. Air Force Office of Scientific Research and Development. An earlier version of this paper was completed in May 1985, during Rao Yu-An's and Wu Yu-Kui's tenures as Visiting Research Scholars in The Perceptual Systems Laboratory, Department of Psychology, UCLA. We thank Morton P. Friedman, R. Edward Geiselman, and Samuel Gilman for help with recording; we thank our subjects, Guican Chen, Jerald Balakrishnan, and Zheng Tang; and we thank Hsuan Hua, Valda Liang, Pearl Burton, Zhong Yuging, and Robert W. Young for their valuable support and concerned interest. Finally, we thank Wu Chong-Ji for playing the bamboo flute. Address correspondence to Rao Yu-An or E. C. Carterette, Department of Psychology, UCLA, Los Angeles, CA 90024 . Wu Yu-Kui is with the Institute of Acoustics at Nanjing University. that are based on various kinds of scales. It is difficult to locate these ancient instruments and then to ascertain that they were used in the practice of music. An even more difficult problem is to determine the relationship of the true pitches of such instruments when the original scales are yet unknown.

Native handmade instruments were based on scales kept alive by local folk musicians. The scale systems were not very strict and sometimes there was considerable variation of an instrument from the scale. Thus the precise experimental comparison of such musical scales is often puzzling because of the difficulty of discovering accurate scale intervals.

The work reported here was an attempt to measure and compare the musical scale of an ancient Chinese bell ensemble with the musical scale of an ordinary modern bamboo flute. To our surprise, we found that the scales are similar except for a few tones.

\section{DESCRIPTION OF THE MUSICAL INSTRUMENTS}

\section{The Bamboo Flute}

The flute (Figure 1) was made recently in Weng-zeu City, China, according to the local traditional scale, which 


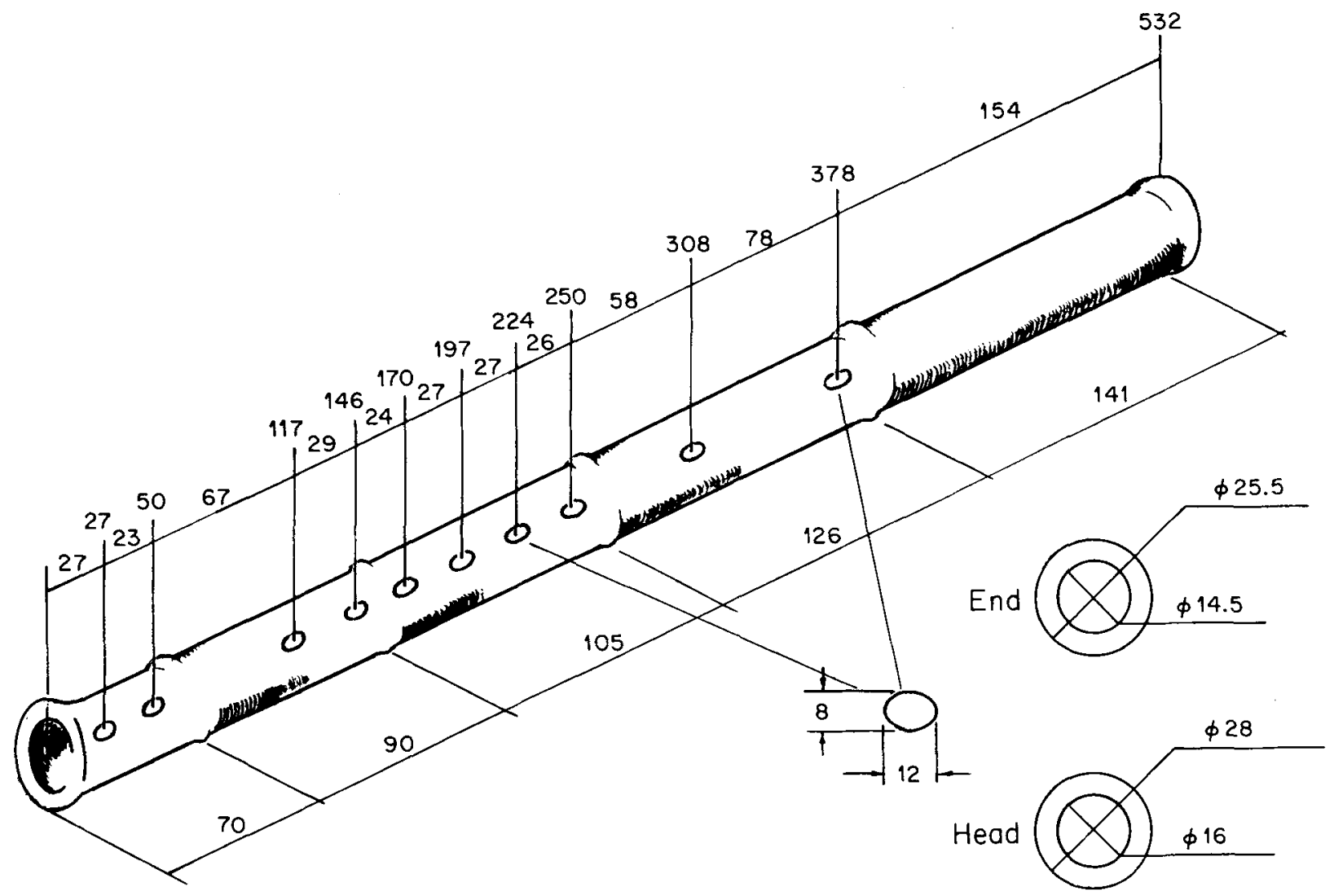

Figure 1. Dimensions of the bamboo flute. Distances are given in millimeters. Figures at the top give distances cumulatively from end to head; figures between lines are distances between points. For example, the flute is $532 \mathrm{~mm}$ long, and the distance from the head to the first hole is $154 \mathrm{~mm}$. The drawing is not to scale except that the end and head openings and the hole diameters are correctly scaled relative to each other, according to pencil rubbings.

was not yet influenced by the 12-tone equal-temperament scale. Made of bamboo and blown transversely, the flute produces 17 tones and is $53.2 \mathrm{~cm}$ long with a slight taper, so that the small-end inner and outer diameters are $14.5 \mathrm{~mm}$ and $25.5 \mathrm{~mm}$, respectively; the corresponding diameters at the large end are $16 \mathrm{~mm}$ and $28 \mathrm{~mm}$. There are 10 oval holes of equal dimensions $(12 \mathrm{~mm}$ across the long axis and $8 \mathrm{~mm}$ across the short axis, with an average diameter of $10 \mathrm{~mm}$ ). Distances to hole centers are shown cumulatively from the small end of the flute. The center of the blow hole is at $378 \mathrm{~mm}$, and the centers of the six tone holes are at 117, 146, 170, 197, 224, and $250 \mathrm{~mm}$. The two leftmost holes (centers at 27 and $50 \mathrm{~mm}$ ) were bored in order to adjust the effective length correctly. Finally, the hole at $308 \mathrm{~mm}$ is covered on the outside with an impermeable membrane derived from the flute's own inner wall. When the flute is played, the vibration of the membrane perceptibly brightens the tones. The drawing, which is not in correct scale, shows the locations of the bamboo joints, but the relative proportions of the holes and the annular ends are correct, having been drawn directly from pencil rubbings of the flute on tissue paper.

Such a flute as this is used by children or amateurs and is not of the type played by musicians today except when the score demands a popular instrument.

\section{The Bells}

There are two ensembles of bells, manufactured about 500 B.C., during the Warring States Period of the Zhou dynasty. One ensemble consists of 64 individual bells ranging in pitch from about 192 to about $1750 \mathrm{~Hz}$. The other ensemble of 13 bells, which we studied in the pitchmaking experiment reported here, covers 2 octaves from about $494 \mathrm{~Hz}$ (B4) to about $1976 \mathrm{~Hz}$ (B6), spanning the same 2 octaves as do the 17 tones of the bamboo flute. The set of bells is shown in Figure 2. The 64-bell set presently resides in Sui Xiang, Hubei Province, although there is now a copy in Beijing. The 13-bell ensemble is now preserved in Chengzhou, Henan Province. (See below for more details.)

A discussion of the manufacture and tuning of bells is given by Needham (1962). The clapperless upward-facing hand bell $(t u)$ was the earliest, dating from about the Zhou dynasty (Feudal Age, 1030-220 B.C.); the clapperless downward-facing hand bell (chung) may be as early as the 6th century B.C. It seems clear that bell technology was well understood in China by the 5th century B.c. Most bells were made of bronze (copper plus $16 \%$ tin), although cast iron was used from an early time. The official records (Zhou $L i$ ) of the Zhou dynasty show that much was known of bells: the shape and proportion of bell parts; the clas- 


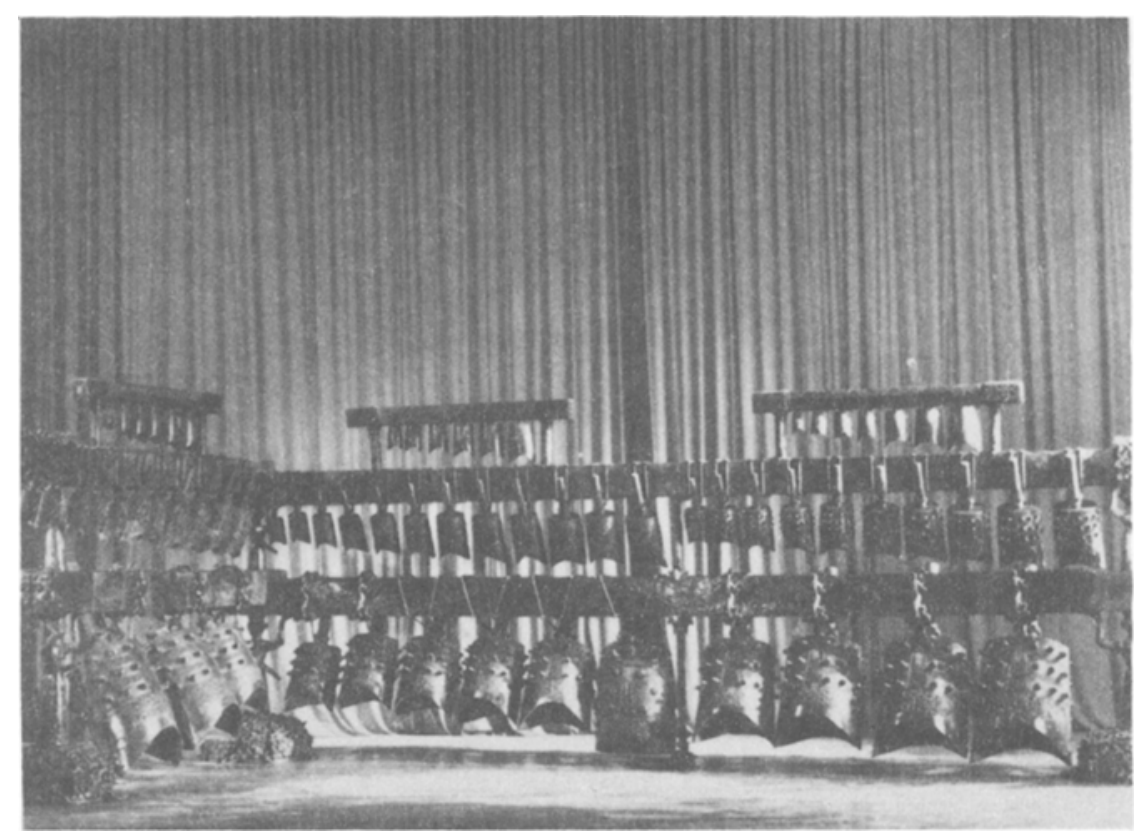

\begin{abstract}
Figure 2. This set of 64 bronze chime bells, which was made in the early Warring States Period (5th century B.c.) of the Zhou dynasty, was unearthed in 1978. It is the largest set yet discovered. Note the middle group of the middle row showing 12 of the bells analyzed in the present study, each of which can sound the independent tones of sui and gu. The sui-gu interval is close to the minor third of the 12-tone equal-temperament scale.
\end{abstract}

sification of harmonics; timbre; and the purifying, preparing, and weighing of metal.

A theory that the Zhou bells each had two pitches has been confirmed by two recent finds (Ma, 1981; Wang, 1981). The 64-bell set was unearthed in 1978 from the tomb of the Marquis of Zeng at Sui Xian Province. The 13-bell set was unearthed in 1957 from the tomb of the emperor Chu in Henan Province. In both sets of bells, the mouth plan is ovoid. The two strike points sui (隧, “"channel") and gu (鼓,"drum") are inscribed on each bell. When the sui is struck the vibration pattern is like that of a true round-section bell. A quarter of the circumference away is struck the $g u$ note, whose fundamental is higher than that of the sui by an interval of about a musical third. According to Ma, the Zhou bells of the Warring States Period make a scale that is fairly close to the modern half-note scale of 12 notes; great accuracy in casting of the bells was required in order to produce the correct intervals. However, the scale is a function of the division of the bells into groups. There is some disagreement between $\mathrm{Ma}$ and Wang about the groupings (Tan \& Guangsheng, 1981).

\section{ACOUSTICAL ANALYSIS OF FLUTE AND BELLS}

\section{General}

The bamboo flute and each bell of the set of 13 bells were played by professional musicians, and each instrument was recorded separately in the studios of a major commercial broadcasting station in Beijing. Recordings were made using a condenser microphone and a magnetic tape recorder (Nagra II).

Measurements were made by routing the electrical output of the tape recorder directly to the input of a Brüel \& Kjaer (B\&K) Type 2033 high-resolution signal analyzer and a B\&K Type $2308 \mathrm{X}-\mathrm{Y}$ recorder. Subsequent pitchmatching experiments were made using a B\&K Type 1023 sine generator whose output was amplified and transduced by a broadcast-quality loudspeaker in a sound-isolated studio with a reverberation time of about $.8 \mathrm{sec}$.

\section{Analysis of the Flute Tones}

The tones of the bamboo flute, which are continuous and nearly stationary although they have a quasi-line spectrum, were analyzed over the 0 to $10 \mathrm{kHz}$ range in the flat setting of the B\&K 2033 signal analyzer, so that time domain records were transformed unmodified by any weighting function. For each of the 17 different flute tones, an automatic scan analysis was carried out on 145 spectra (64 samples in each scan), which resulted in a linearly averaged spectrum with a relative error of less than $0.35 \mathrm{~dB}$ in amplitude. Figure 3 shows the averaged spectra of tone 5 (a pitch of $725 \mathrm{~Hz}$ ) and tone 4 (a pitch of $650 \mathrm{~Hz}$ ).

Usually, the frequency of a stationary complex sound is specified by its fundamental and harmonic structure. Here the 17 tones of the flute have been determined both by computing their spectra and by pitch judgments. Even under ideal conditions (where the subjective pitch fre- 


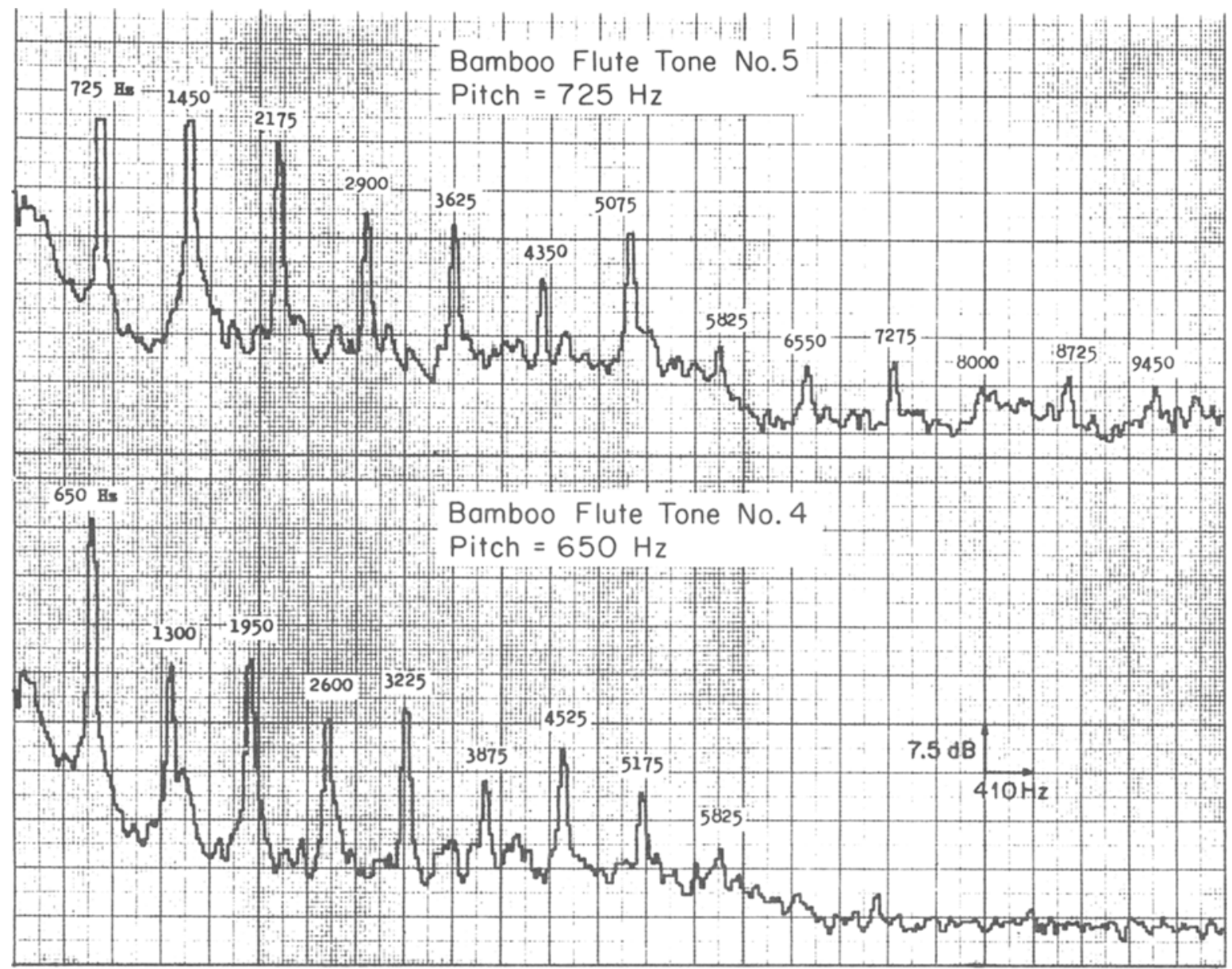

Figure 3. Linearly averaged, unweighted amplitude spectra of bamboo flute tones 4 (a pitch of $650 \mathrm{~Hz}$ ) and 5 (a pitch of $725 \mathrm{~Hz}$ ). The vertical scale line is $7.5 \mathrm{~dB}$ long and the horizontal scale line is $410 \mathrm{~Hz}$ long. See text for details of physical and subjective analyses.

quency was equal to the physical frequency), differences between computed and judged frequencies could have arisen from the $25-\mathrm{Hz}$ resolution limit at the full-scale frequency setting ( $10 \mathrm{kHz})$ used, and from airflow fluctuations at the flutist's lip. Table 1 shows the value in hertz of the computed harmonic components of the 17 flute tones and their calculated pitches. Note that seven components are shown for tones $1-5$, with six to two components given for higher pitches.

\section{Analysis of the Bell Tones (Sui Notes)}

For analysis of the transient sound of the bell, the proper unit is energy density, since the spectrum is essentially continuous rather than a line spectrum, as in the case of the flute. And the partials of bells are not harmonics of some fundamental. Hence the B\&K 2033 signal analyzer was used with a Hanning weighting function to carry out an automatic scan analysis over the $10-\mathrm{kHz}$ records of the individual bell tones. In the case of each sui-note bell tone, 73 spectra were scanned at 128 samples per step. The linear average of scanned spectra resulted in spectra like those shown in Figures 4, 5, and 6. Figure 4 shows the amplitude versus frequency spectra of bell tones 3
Table 1

The Computed Fundamentals (Rightmost Column) and the Series of Harmonic Partials of the 17 Bamboo Flute Tones as Calculated on 145 Unweighted Spectra (64 Samples per Scan), Using the Brüel \& Kjaer Type 2300 High-Resolution Signal Analyzer

\begin{tabular}{crrrrrrrl}
\hline \multirow{2}{*}{$\begin{array}{c}\text { Tone } \\
\text { Number }\end{array}$} & \multicolumn{1}{c}{ Partial Number } & \multicolumn{1}{c}{ Computed } \\
\cline { 2 - 7 } & 1 & 2 & 3 & 4 & 5 & 6 & 7 & Partial 1 \\
\hline 1 & 475 & 975 & 1475 & 1950 & 2480 & 2925 & 3425 & 500 \\
2 & 525 & 1075 & 1600 & 2125 & 2675 & 3200 & 3750 & $525-550$ \\
3 & 600 & 1200 & 1775 & 2375 & 2975 & 3575 & 4150 & 600 \\
4 & 650 & 1300 & 1950 & 2600 & 3225 & 3875 & 4525 & 650 \\
5 & 725 & 1450 & 2175 & 2900 & 3625 & 4350 & 5075 & 725 \\
6 & 825 & 1150 & 2475 & 3300 & 4125 & 4950 & 825 \\
7 & 900 & 1775 & 2675 & 3575 & 4450 & $(5125)$ & $875-900$ \\
8 & 950 & 1900 & 2850 & 3775 & 4725 & & 950 \\
9 & 1000 & 2000 & 3000 & 4000 & 5000 & 6000 & 1000 \\
10 & 1100 & 2175 & 3275 & 4375 & 5450 & & $1075-1100$ \\
11 & 1200 & 2400 & 3625 & 4825 & $(5125)$ & & $1200-1225$ \\
12 & 1325 & 2650 & 3975 & & & & 1325 \\
13 & 1475 & 2950 & 4450 & $(5125)$ & 5925 & & $1475-1500$ \\
14 & 1650 & 3300 & 4975 & $(5125)$ & & & $1650-1675$ \\
15 & 1800 & 3625 & $(5125)$ & 5425 & & & $1800-1825$ \\
16 & 1875 & 3750 & 5125 & & & & 1875 \\
17 & 2000 & 4000 & 6000 & & & & 2000 \\
\hline
\end{tabular}

Note-All values are in hertz. Values in parentheses (5125) were the best choice of two close local peaks. 


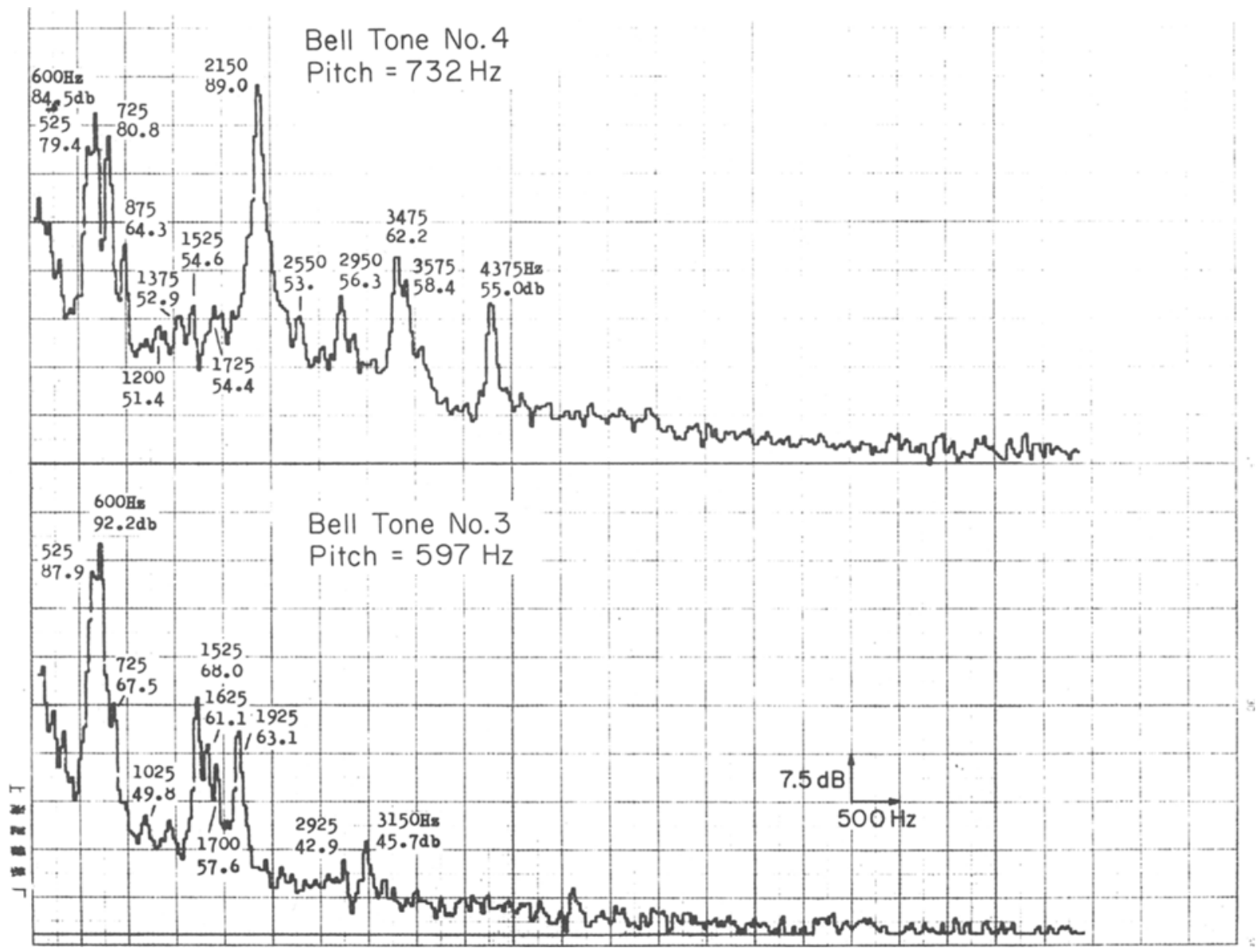

Figure 4. Linearly averaged, Hanning-weighted amplitude spectra of bell tones 3 (a pitch of $597 \mathrm{~Hz}$ ) and 4 (a pitch of $732 \mathrm{~Hz}$ ). The vertical scale line is $7.5 \mathrm{~dB}$ long and the horizontal scale line is $500 \mathrm{~Hz}$ long.

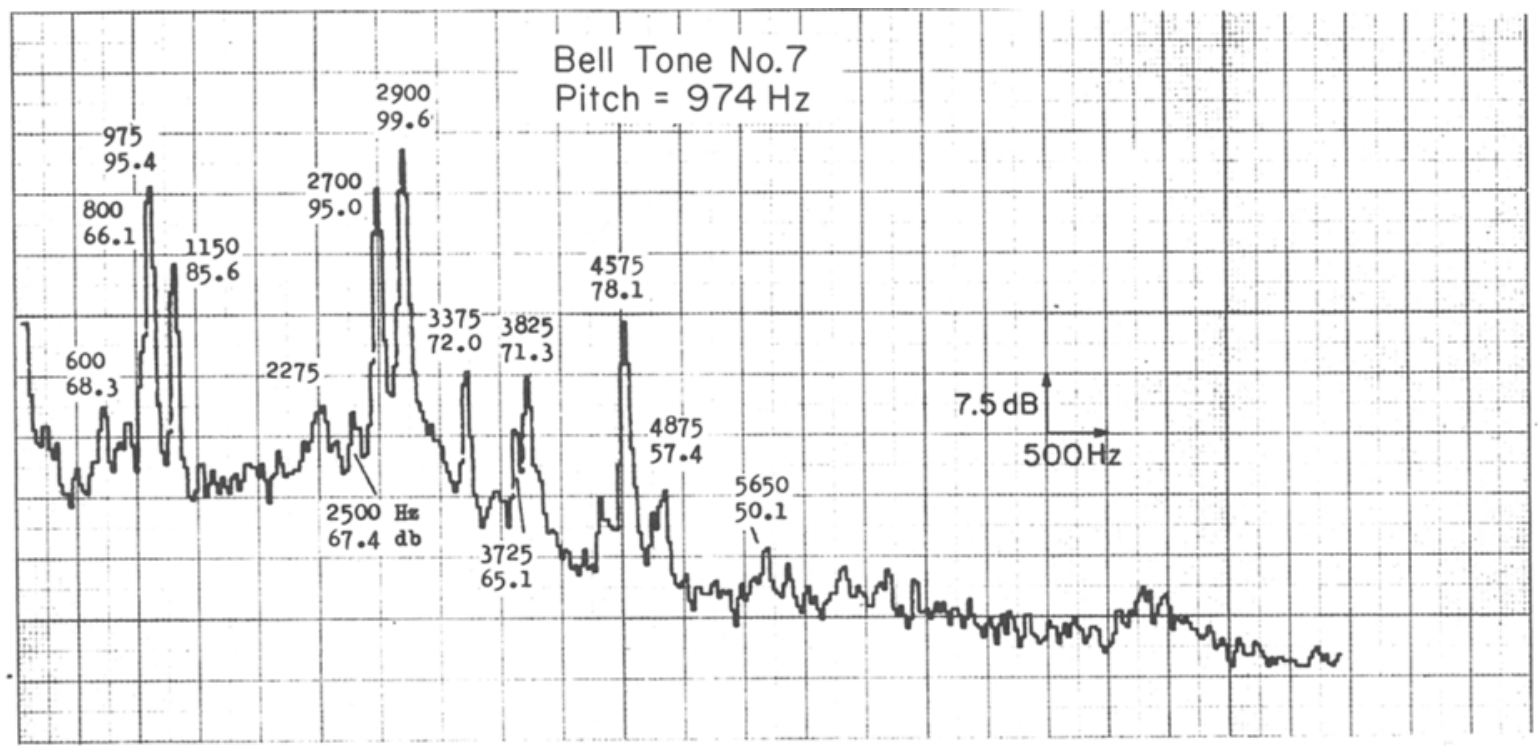

Figure 5. Linearly averaged, Hanning-weighted amplitude spectrum of bell tone 7 (a pitch of $974 \mathrm{~Hz}$ ). The vertical scale line is $7.5 \mathrm{~dB}$ long and the horizontal scale line is $500 \mathrm{~Hz}$ long. 


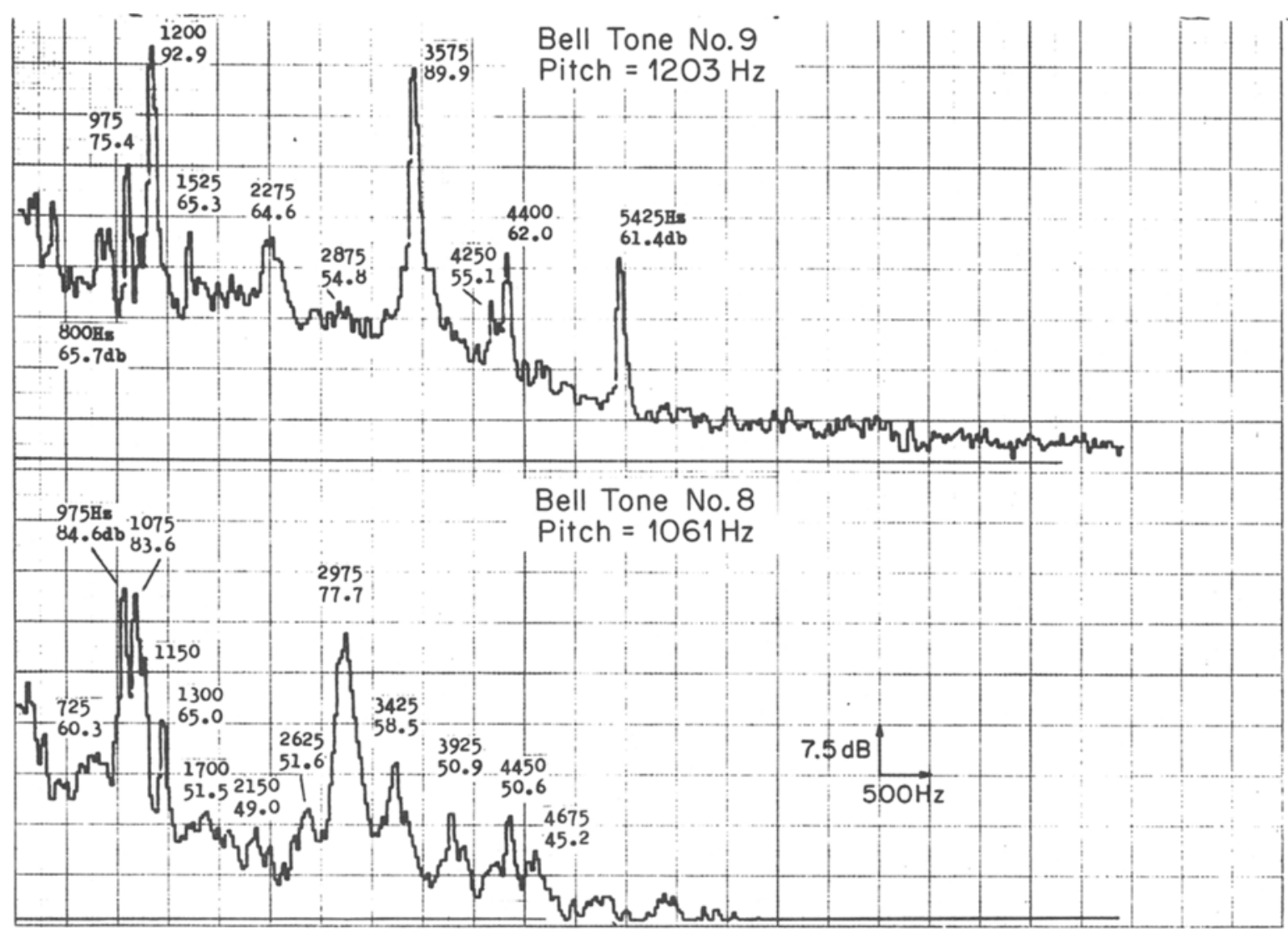

Figure 6. Linearly averaged, Hanning-weighted amplitude spectra of bell tones 8 (pitch of $1061 \mathrm{~Hz}$ ) and 9 (pitch of 1203 Hz). The vertical scale line is $7.5 \mathrm{~dB}$ long and the horizontal scale line is $500 \mathrm{~Hz}$ long.

$(597 \mathrm{~Hz})$ and $4(732 \mathrm{~Hz})$. Figure 5 shows the spectrum of bell tone $7(974 \mathrm{~Hz})$ and Figure 6 shows the spectra of bell tones $8(1061 \mathrm{~Hz})$ and $9(1203 \mathrm{~Hz})$. The fundamental frequencies (e.g., $597 \mathrm{~Hz})$ given here in parentheses are for pitch and were experimentally found as described in the section on subjective pitch analysis below.

The above spectral analyses were done in Shanghai, China, using the B\&K 2033 signal analyzer. Independent analyses were done in the United States, using another system. The same sounds were analyzed by a HewlettPackard real-time precision wave analyzer (Type 3561A) and a graphics plotter (Hewlett-Packard Type 7550A). The obtained spectra were essentially identical to those obtained in China using the B\&K 2033 signal analyzer.

We point out that the spectra of these ancient Chinese bells are very complex and are far from being line spectra. They are more like the formants of speech, whereas the spectra of the tones of the bamboo flute are very close to being pure line spectra. These spectral differences are related to our perception of the flute as ethereal and the bell as more human. Indeed, bells are often called by particular names, such as London's Big Ben, Cologne Cathedral's Gloriosa, and the various bells of Dorothy $L$. Sayers's mystery, The Nine Tailors.

\section{SUBJECTIVE PITCH MATCHES OF FLUTE AND BELL TONES}

\section{Bamboo Flute and Zhou Bells}

Pitch matches made in China. The (subjective) pitch of a complex nonstationary bell sound containing inharmonic components cannot be predicted or computed easily from theory. As Figures 4, 5, and 6 show, the pitch depends neither on the fundamental frequency of a struck tone (e.g., the sui note) nor on the major amplitude peaks of a partial nor on partial intervals. Therefore, the pitch of a bell note was determined from hearing alone by a matching procedure.

In order to compare the ancient scale of the bells with that of the modern bamboo flute, pitch matches were made of pure sine tones to the 17 tones of the flute and to the 13 tones of the bells. Both bell tones and flute tones were heard over a broadcast monitor loudspeaker in a soundisolated listening room. Pitch matches were made by adjusting the frequency of the B\&K 1023 sine generator, whose output was heard over another monitor loudspeaker separated in space by $45^{\circ}$ from the loudspeaker that played the bell or flute tone. Musical tones were alternated with sine tones, with a silent interval of about $500 \mathrm{msec}$. Listeners sat at a distance of $1.5 \mathrm{~m}$ from each loudspeaker. 
Two male listeners each made two matches of frequency of the sine generator to each of the 17 tones of the flute and 13 tones of the bells. The listeners were 22 years of age and had normal audiograms and more than 2 years of extensive experience as observers in psychoacoustic experiments. They could hear a given tone as often as desired until an acceptable pitch match was made.

Pitch matches were made with the sine tone at about $70 \mathrm{~dB}$ SPL at the listener's ear. Flute tones ranged between 65 and $73 \mathrm{~dB}$, and to these, pitch matches were easy. Since a given bell has a singular decay rate of both fundamental and partials, the listener made a best match on the basis of the bell's complex timbral sound during the initial steady-state period of the clang, that is, during the first 2 sec of the decaying sound. Individual clangs were 76 to $81 \mathrm{~dB}$ SPL at onset. The results of the pitch matches are shown in Table 2 (Column 5 for the flute, and Column 8 for the bells).

Pitch matches made in the United States. A second group of subjects was run in the United States in order to increase the reliability of the pitch judgments. Five musically trained listeners matched each of the 13 bell tones and 17 flute tones with a sine tone.

The sine waves arose from a voltage-controlled generator (Wavetek 116), which was driven by a digital-toanalog converter (DAC; Hewlett-Packard 12062A) to a resolution of $5 \mathrm{mV}$ or $1 \mathrm{~Hz}$. The actual frequency values in hertz were read from an electronic counter (HewlettPackard 5512A).

The musical tones were played back from the original tapes (described above) via a precision magnetic recorder (Sony TC-D5M) whose electrical output was band-pass filtered (Krohn-Hite 3020 ) at $40 \mathrm{~Hz}-10 \mathrm{kHz}$ and then passed through a data amplifier (Hewlett-Packard 2470A) before storing in digital form on disk (Hewlett-Packard 7945). Analog-to-digital conversion (Hewlett-Packard $12060 \mathrm{~B}$ converter) was done at 12 bits every $50 \mu \mathrm{sec}$ (20,000 samples per second). Playback of the digital samples was done under computer control at a sampling period of $50 \mu \mathrm{sec}$ of 12-bit words via a DAC (Hewlett-Packard 12062A). The samples were passed through a Cauer desampling filter with a low-pass cutoff of $9720 \mathrm{~Hz}$ whose

Table 2

Data From 2 Subjects Tested in China

\begin{tabular}{|c|c|c|c|c|c|c|c|c|c|}
\hline \multirow[b]{2}{*}{ No. } & \multicolumn{6}{|c|}{ Bamboo Flute } & \multicolumn{3}{|c|}{ Zhou Bells } \\
\hline & $\begin{array}{c}\text { Computed } \\
\text { Frequency (Hz) }\end{array}$ & $\begin{array}{c}\text { Nearest } \\
\text { Note }\end{array}$ & $\begin{array}{l}\text { Interval } \\
\text { (Cents) }\end{array}$ & $\begin{array}{l}\text { Pitch } \\
(\mathrm{Hz})\end{array}$ & $\begin{array}{c}\text { Nearest } \\
\text { Note }\end{array}$ & $\begin{array}{l}\text { Interval } \\
\text { (Cents) }\end{array}$ & $\begin{array}{l}\overline{\text { Pitch }} \\
(\mathrm{Hz})\end{array}$ & $\begin{array}{c}\text { Nearest } \\
\text { Note }\end{array}$ & $\begin{array}{l}\text { Interval } \\
\text { (Cents) }\end{array}$ \\
\hline 1 & 500 & B4 & 84.2 & 485 & B4-31 & 153.6 & 491 & B4 - 10 & 148.6 \\
\hline 2 & 525 & $\mathrm{C} 5+6$ & 231.2 & 530 & $\mathrm{C} 5+22$ & 188.9 & 535 & $\mathrm{C} 5+34$ & 189.8 \\
\hline 3 & 600 & D5 + 37 & 138.6 & 591 & $\mathrm{D} 5+11$ & 154.1 & 597 & $\mathrm{D} 5+28$ & \\
\hline 4 & 650 & E5-24 & 189.0 & 646 & E5-35 & 199.7 & & & 352.9 \\
\hline 5 & 725 & $F \$ 5-35$ & 223.7 & 725 & $F \square 5-35$ & 211.1 & 732 & $F \$ 5-19$ & 192.9 \\
\hline 6 & 825 & G5-12 & 101.9 & 819 & G5-24 & 134.2 & 818 & G5-26 & \\
\hline 7 & 875 & A5 -10 & 142.4 & 885 & $A 5+10$ & 102.5 & & & 214.7 \\
\hline 8 & 950 & $A \$ 5+33$ & 88.8 & 939 & $A \$ 5+12$ & 93.3 & 926 & $A \not 5-11$ & 87.5 \\
\hline 9 & 1000 & B5 +22 & 125.2 & 991 & B5 +6 & 160.1 & 974 & B5 -24 & 148.1 \\
\hline 10 & 1075 & $\mathrm{C} 6+47$ & 190.4 & 1087 & $C \$ 6-34$ & 169.8 & 1061 & $\mathrm{C} 6+24$ & 217.5 \\
\hline 11 & 1200 & D6 +37 & 171.6 & 1199 & $D 6+36$ & 161.2 & 1203 & D $6+42$ & 301.7 \\
\hline 12 & 1325 & E6 +6 & 185.7 & 1316 & & 205.7 & & & \\
\hline 13 & 1475 & $F \sharp 6-6$ & 194.1 & 1482 & $F \$ 6+3$ & 189.0 & 1432 & $F 6+43$ & 194.2 \\
\hline 14 & 1650 & $G \$ 6-12$ & 174.5 & 1653 & $G \$ 6-8$ & 164.7 & 1602 & $G 6+37$ & 148.0 \\
\hline 15 & 1825 & A $6-37$ & 46.8 & 1818 & $A: 6-44$ & 60.8 & 1745 & A6-14 & 483.3 \\
\hline 16 & 1875 & $A \$ 6+10$ & 111.7 & 1883 & $A \$ 6+17$ & 129.3 & & & \\
\hline 17 & 2000 & B $6+21$ & & 2029 & $\mathrm{~B} 6+46$ & & 2307 & D7-31 & \\
\hline
\end{tabular}

Note-In the case of the 17 flute tones, Column 2 shows the computed fundamental frequency, Column 3 the name of the nearest note, and Column 4 the interval between adjacent notes in cents; mean pitch is given in Column 5, with nearest note and interval between notes in Columns 6 and 7 . In the case of the 13 Zhou bells, the corresponding pitches, nearest notes, and intervals are tabled in the rightmost three columns. 
attenuation was $45 \mathrm{~dB}$ at $12 \mathrm{kHz}$. The resulting sound quality was excellent, as might be expected from the 78-dB signal-to-noise ratio that was achieved $[20 \log (4195 / .5)]$.

The listeners heard the sounds binaurally over a headset (matched TDH-49 earphones, MX-41 cusions). Playback and control of the experiment was by means of computer (Hewlett-Packard A900). The listener sat in a chair in an anechoic room and pressed buttons on a keyboard in order to alter the pitch of a pure tone. The instructions were very simple: "Change the pitch of the tone in the second interval until you feel that it matches the pitch of the flute or bell sound in the first interval. You may listen as long as you like. When you have made a match press the key labeled zero." The listener could change the frequency up or down in either fine steps $(1 \mathrm{~Hz})$ or coarse steps $(8 \mathrm{~Hz})$ by a keypress. The 1.5-sec duration of each tone was signaled by a light panel. A left light was lit while the flute or bell tone sounded; then, after a 400 -msec silence, a right light was lit while the pure tone sounded. A pair of lights signaled the response interval (a maximum of $3 \mathrm{sec}$ ) during which the listener could press a key to change the frequency. As soon as the response key was pressed the next cycle of tones was played.

The 5 listeners were males aged 25 to 46 . All could read music and had had at least 5 years' formal instruction on a musical instrument. Each listener made five matches of the pure tone to each of the 13 bell tones and to each of the 17 flute tones. In a given session all tones of one instrument were heard in a random order. Each match trial began with a random setting of the frequency of the pure tone above or below the neighborhood of the mean perceived pitch of the instrument tone. In all there were 5,525 pitch matches, because each of the 5 listeners made 1,105 pitch matches: 5 (sessions) $\times 13$ (bell tones) $\times 17$ (flute tones).
Each resulting mean pitch value shown in Table 3 is based on 25 matches ( 5 listeners $\times 5$ sessions). The average pitch match is shown for each bell and flute tone, as is its standard deviation. These data are very similar to those obtained in China using loudspeakers and manual adjustment of frequency (Table 2), as statistical tests show. The means of the pitch matches made in China and in the United States are not significantly different for the bells $[t(24)=0.05]$ or for the flute tones $[t(32)=-0.06]$. For purposes of later analyses and discussion, the data of Table 2 are used in order to keep the cultural background homogeneous.

\section{The Sui-Gu Interval of Zhou Bells}

On a set of 13 bells similar to those we have analyzed, Ma (1981) gave physical values of fundamental frequencies for sui and $g u$ notes. Based on accelerometry, both frequency and amplitude patterns were found for different striking positions on the rim of the bell, whose mouth is oval. The sui note is the fundamental and arises from a strike on the rim of the bell at the center of the arc of least curvature (i.e., where the tangent of the arc is parallel to the long axis of the ellipsoid); the $g u$ note is struck about halfway between sui and the center of the arc of greatest curvature. Sui and $g u$ form a musical interval of about a third.

For the 13 notes he measured, Ma (1981) gave the deviations (in cents) of the sui notes from the nearest equaltemperament notes. From Ma's values we computed the mean deviation to be -27.0 cents, with a standard deviation of 19.3 cents (Table 4, Column 3). Table 4, Column 5 shows the mean deviation of (subjective) pitch of the sui from the nearest equal-temperament note to be +5.62 cents, with a standard deviation of 28.98 cents. Ma's deviations are negative in 11 of the 13 bells and the

Table 3

Data From 5 Subjects Tested in the United States

\begin{tabular}{|c|c|c|c|c|c|c|c|c|c|}
\hline \multirow{2}{*}{$\frac{\text { Bell }}{b_{1}}$} & \multicolumn{2}{|c|}{$\begin{array}{c}\text { Mean Pitch Match } \\
(P, \text { in } \mathrm{Hz})\end{array}$} & \multirow{2}{*}{$\begin{array}{c}S D(\mathrm{~Hz}) \\
2.63\end{array}$} & \multirow{2}{*}{$\frac{100(P / S D)}{0.53 \%}$} & \multirow{2}{*}{$\frac{\text { Flute }}{f_{t}}$} & \multicolumn{2}{|c|}{$\begin{array}{c}\text { Mean Pitch Match } \\
(P, \text { in } \mathrm{Hz})\end{array}$} & \multirow{2}{*}{$\frac{S D(\mathrm{~Hz})}{3.68}$} & \multirow{2}{*}{$\frac{100(P / S D)}{0.76 \%}$} \\
\hline & 500.20 & $(500)$ & & & & 481.68 & $(500)$ & & \\
\hline$b_{2}$ & 530.44 & (525) & 6.22 & $1.17 \%$ & $f_{2}$ & 529.56 & (525) & 1.66 & $0.31 \%$ \\
\hline$b_{3}$ & 609.56 & $(600)$ & 5.53 & $0.91 \%$ & $f_{3}$ & 585.24 & $(600)$ & 2.95 & $0.50 \%$ \\
\hline$b_{4}$ & 718.28 & (725) & 6.82 & $0.95 \%$ & $f_{4}$ & 637.24 & (650) & 2.41 & $0.38 \%$ \\
\hline$b_{5}$ & 807.24 & $(800)$ & 2.53 & $0.31 \%$ & $f_{5}$ & 720.52 & (725) & 5.78 & $0.80 \%$ \\
\hline$b_{6}$ & 905.08 & $(900)$ & 14.53 & $1.61 \%$ & $f_{6}$ & 804.64 & (825) & 8.33 & $1.04 \%$ \\
\hline$b_{7}$ & 966.76 & (975) & 8.46 & $0.88 \%$ & $\hat{\mathbf{I}_{7}}$ & 874.88 & (875) & 6.54 & $0.75 \%$ \\
\hline$b_{8}$ & 1098.24 & (1075) & 23.45 & $2.14 \%$ & $f_{8}$ & 932.68 & (950) & 5.46 & $0.59 \%$ \\
\hline$b_{9}$ & 1198.16 & $(1200)$ & 16.15 & $1.35 \%$ & $f_{9}$ & 984.48 & $(1000)$ & 8.58 & $0.87 \%$ \\
\hline$b_{10}$ & 1462.28 & (1450) & 5.54 & $0.38 \%$ & $f_{10}$ & 1086.20 & (1075) & 4.36 & $0.40 \%$ \\
\hline$b_{11}$ & 1625.48 & (1625) & 9.64 & $0.59 \%$ & $f_{11}$ & 1192.08 & (1200) & 5.81 & $0.48 \%$ \\
\hline$b_{12}$ & 1801.88 & $(1800)$ & 7.49 & $0.42 \%$ & $f_{12}$ & 1310.96 & (1325) & 6.72 & $1.0 \%$ \\
\hline$b_{13}$ & 2341.24 & (2325) & 28.81 & $1.23 \%$ & $f_{13}$ & 1467.08 & (1475) & 4.61 & $0.31 \%$ \\
\hline & & & & & 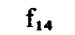 & 1643.24 & (1650) & 4.84 & $0.29 \%$ \\
\hline & & & & & $f_{15}$ & 1795.84 & (1825) & 7.37 & $0.41 \%$ \\
\hline & & & & & $f_{16}$ & 1865.24 & (1875) & 7.06 & $0.38 \%$ \\
\hline & & & & & $f_{17}$ & 1986.34 & $(2000)$ & 8.78 & $0.44 \%$ \\
\hline
\end{tabular}

Note-Mean pitch match in hertz is shown for each of the 13 beil tones and 17 flute tones, together with the standard deviation (in hertz) and the coefficient of variation in percent $[100 \times(P / S D)]$. Values shown in parentheses are the respective physical frequencies (in hertz) corresponding to each pitch match. 
Table 4

Distance to the Nearest Note of the Equal-Temperament Scale of the 13 Zhou-Bell Physical Frequencies

\begin{tabular}{|c|c|c|c|c|}
\hline Bell & $\begin{array}{c}\text { Sui } \\
\text { (Measured, Hz) } \\
(\mathrm{Ma}, 1981)\end{array}$ & $\begin{array}{l}\text { Distance to } \\
\text { Nearest Note } \\
\text { (Cents) }\end{array}$ & $\begin{array}{c}\text { Sui } \\
\text { (Pitch, Hz) } \\
\text { (This Study) }\end{array}$ & $\begin{array}{l}\text { Distance to } \\
\text { Nearest Note } \\
\text { (Cents) }\end{array}$ \\
\hline 1 & 508.5 & $B \$ 4-50$ & 491 & B4 -10 \\
\hline 2 & 542.3 & C 5-38 & 535 & C5 +34 \\
\hline 3 & 608.0 & D\$5-40 & 597 & D5 +28 \\
\hline 4 & 729.9 & F:5-24 & 732 & $F \$ 5-19$ \\
\hline 5 & 812.6 & G $\$ 5-38$ & 818 & G5 -26 \\
\hline 6 & 911.1 & $A-5-40$ & 926 & A $\$ 5-11$ \\
\hline 7 & 982.5 & B5 -10 & 974 & B5 -24 \\
\hline 8 & 1092.0 & C $6-26$ & 1061 & $\mathrm{C} 6+24$ \\
\hline 9 & 1213.5 & D\$6-44 & 1203 & D6 +42 \\
\hline 10 & 1483.6 & $F 6+4$ & 1432 & $F 6+43$ \\
\hline 11 & 1649.6 & $G 6-12$ & 1602 & $F 6+37$ \\
\hline 12 & 1819.1 & $A \square-43$ & 1745 & A6-14 \\
\hline 13 & 2363.3 & $\mathrm{D} 7+10$ & 2307 & D7 -31 \\
\hline \multicolumn{2}{|c|}{$\begin{array}{l}\text { Mean Distance (Cents) } \\
S D \text { (Cents) }\end{array}$} & $\begin{array}{r}-27.0 \\
19.3\end{array}$ & & $\begin{array}{r}+5.6 \\
28.9\end{array}$ \\
\hline
\end{tabular}

nearest note is sharp in 9 cases. Our deviations are negative in 6 cases and positive in 7 cases and the nearest note is sharp in only 2 cases (Bell 4, F $\$ 5$ and Bell 6, A $\$ 5$ ). These differences were to be expected, since Ma's physical (accelerometer-based) values arose from a different kind of measurement than did our pitch measurements. Taking into account the probable means at the disposal of the ancient bell makers, we believe that pitch is the more valid criterion for comparing Zhou scales with our contemporary scales. McClain (1985) suggested, on the basis of coincidences between abstract Chinese tone ratios and measured frequencies of the largest Zeng bells, that Zeng acousticians may have been able to make accurate frequency determinations. Even if this is true, the ultimate arbiter of the working pitch of a bell is the listener.

\section{RESULTS AND DISCUSSION}

\section{Comparison of the Scales of Some Ancient Zhou Bells and a Modern Bamboo Flute}

The bamboo flute of Weng-Zhou City was made some 2.5 millenia after the Zhou bells were cast, yet there are some striking similarities in the pitches and the intervals of the two musical instruments. In Table 5, Column 5, we see that the mean pitch difference over the first 12 tones is $17 \mathrm{~Hz}$. Bell 13 has been excluded in making the main points because it is $278 \mathrm{~Hz}$ higher in pitch than flute tone 17 , suggesting that at least two bells are missing from the sequence between $1745 \mathrm{~Hz}$ and $2307 \mathrm{~Hz}$.

The mean difference in intervals of flute and bell tones is -7.33 cents (Column 8 ), with a standard deviation of 26.41 cents; the Pearson product-moment correlation of bell and flute intervals (in cents) is 0.95 . These facts, taken together with the fact that 6 of the 11 interval differences are less than 7 cents, suggest that the modern flute scale and the ancient bell scale are closely related.

Table 5

Pitch, Pitch Differences, Intervals, and Interval Differences for the Zhou Bells and Flute

\begin{tabular}{|c|c|c|c|c|c|c|c|c|}
\hline \multirow{2}{*}{\multicolumn{2}{|c|}{ Number }} & \multirow{2}{*}{\multicolumn{2}{|c|}{ Pitch $(\mathrm{Hz})$}} & \multicolumn{2}{|c|}{ Pitch Difference } & \multirow{2}{*}{\multicolumn{2}{|c|}{ Interval (Cents) }} & \multirow{3}{*}{$\begin{array}{c}\text { Interval Difference } \\
\text { (Flute-Bell, } \\
\text { in Cents) }\end{array}$} \\
\hline & & & & \multirow{2}{*}{$\begin{array}{c}\text { Flute-Bell } \\
(\mathbf{H z})\end{array}$} & \multirow{2}{*}{$\begin{array}{c}\text { Signed } \\
\text { Deviation }\end{array}$} & & & \\
\hline Bell & Flute & Bell & Flute & & & Bell & Flute & \\
\hline \multicolumn{9}{|c|}{ Data From the 2 Subjects Tested in China } \\
\hline 1 & 1 & 491 & 485 & -6 & $-1.23 \%$ & 148.6 & 153.6 & 5.0 \\
\hline 2 & 2 & 535 & 530 & -5 & $-.94 \%$ & 189.8 & 188.9 & \\
\hline 3 & 3 & 597 & 591 & -6 & $-1.02 \%$ & 352.9 & 353.8 & .9 \\
\hline 4 & 5 & 732 & 725 & -7 & $-.97 \%$ & 192.9 & 199.7 & 6.8 \\
\hline 5 & 6 & 818 & 819 & 1 & $.12 \%$ & 214.7 & 236.7 & 22.0 \\
\hline 6 & 8 & 926 & 939 & 13 & $1.28 \%$ & 87.5 & 93.3 & 5.8 \\
\hline 7 & 9 & 974 & 991 & 17 & $1.72 \%$ & 148.1 & 160.1 & 12.0 \\
\hline 8 & 10 & 1061 & 1087 & 26 & $2.39 \%$ & 217.5 & 169.8 & -47.7 \\
\hline 9 & 11 & 1203 & 1199 & -4 & $-.33 \%$ & 301.7 & 366.9 & 65.2 \\
\hline 10 & 13 & 1423 & 1482 & 50 & $.37 \%$ & 194.2 & 189.0 & -5.2 \\
\hline 11 & 14 & 1602 & 1653 & 51 & $3.09 \%$ & 148.0 & 164.7 & 16.7 \\
\hline 12 & 15 & 1745 & 1818 & 73 & $4.20 \%$ & 433.3 & 190.1 & -243.2 \\
\hline 13 & 17 & 2307 & 2029 & -278 & $-13.70 \%$ & & & \\
\hline & $\begin{array}{l}\mathbf{M} \\
S\end{array}$ & & & $\begin{array}{l}16.9 \\
27.4\end{array}$ & $\begin{array}{l}.97 \% \\
1.93\end{array}$ & $\begin{array}{r}199.6 \\
74.3\end{array}$ & $\begin{array}{r}206.9 \\
83.9\end{array}$ & $\begin{array}{r}-7.3 \\
26.4\end{array}$ \\
\hline
\end{tabular}


Table 5 (Continued)

\begin{tabular}{|c|c|c|c|c|c|c|c|c|}
\hline \multirow{2}{*}{\multicolumn{2}{|c|}{ Number }} & \multirow{2}{*}{\multicolumn{2}{|c|}{ Pitch (Hz) }} & \multicolumn{2}{|c|}{ Pitch Difference } & \multirow{2}{*}{\multicolumn{2}{|c|}{ Interval (Cents) }} & \multirow{3}{*}{$\begin{array}{c}\text { Interval Difference } \\
\text { (Flute-Bell, } \\
\text { in Cents) }\end{array}$} \\
\hline & & & & \multirow{2}{*}{$\begin{array}{l}\text { Flute - Bell } \\
(\mathrm{Hz})\end{array}$} & \multirow{2}{*}{$\begin{array}{c}\text { Signed } \\
\text { Deviation }\end{array}$} & & & \\
\hline Bell & Flute & Bell & Flute & & & Bell & Flute & \\
\hline \multicolumn{9}{|c|}{ Data From All 7 Subjects } \\
\hline 1 & 1 & 495.6 & 483.4 & 12.1 & $2.36 \%$ & & & \\
\hline & & & & & & 124.9 & 158.8 & -33.8 \\
\hline 2 & 2 & 532.7 & 529.8 & -2.9 & $-.55 \%$ & 215.4 & & \\
\hline 3 & 3 & 603.3 & 588.1 & -15.2 & $-2.50 \%$ & & & \\
\hline & & & & & & 318.6 & 357.0 & -38.4 \\
\hline 4 & 5 & 725.2 & 722.8 & -2.4 & $-.44 \%$ & & & \\
\hline 5 & 6 & 812.6 & 811.8 & -0.8 & $-.10 \%$ & 190.9 & 201.0 & -13.1 \\
\hline & & & & & & 205.7 & 246.0 & -40.3 \\
\hline 6 & 8 & 915.1 & 935.8 & 20.7 & $2.24 \%$ & 100.6 & 93.6 & +70 \\
\hline 7 & 9 & 970.4 & 987.8 & 17.4 & $1.84 \%$ & & & \\
\hline & & & & & & 184.6 & 164.8 & +19.7 \\
\hline 8 & 10 & 1079.6 & 1086.5 & 6.9 & $.64 \%$ & & & \\
\hline 9 & 11 & 1200.6 & 1195.6 & -5.0 & $-.42 \%$ & 183.0 & 165.6 & +18.2 \\
\hline & & & & & & 318.8 & 362.9 & -44.9 \\
\hline 10 & 13 & 1442.7 & 1474.5 & 31.8 & $2.18 \%$ & & & \\
\hline & & & & & & 194.0 & 192.6 & +1.5 \\
\hline 11 & 14 & 1613.8 & 1648.1 & 34.3 & $2.10 \%$ & & & \\
\hline $\begin{array}{l}12 \\
13\end{array}$ & $\begin{array}{l}15 \\
17\end{array}$ & $\begin{array}{l}1776.9 \\
2324.1\end{array}$ & $\begin{array}{l}1806.9 \\
2007.0\end{array}$ & 30.0 & $1.67 \%$ & 166.6 & 159.2 & +7.4 \\
\hline & $\begin{array}{l}M \\
S \\
\end{array}$ & & & $\begin{array}{l}10.4 \\
11.9 \\
\end{array}$ & $\begin{array}{r}.75 \% \\
1.55 \% \\
\end{array}$ & $\begin{array}{r}191.7 \\
55.8 \\
\end{array}$ & $\begin{array}{r}207.5 \\
83.8 \\
\end{array}$ & $\begin{array}{r}-7.4 \\
23.5 \\
\end{array}$ \\
\hline
\end{tabular}

Note-The interval between Bells 12 and 13 (433.3 cents) is so large relative to the interval between flute tones 15 and 17 (190.1 cents) that the statistical summary excludes this interval difference. In fact, 433.3 cents lies more than 3 standard deviations above the mean of the preceding 11 intervals. Mean and $S D$ do not include bell interval 12-13 or flute interval 15-17.

The similarity of bell and flute scales is reinforced by closeness of the mean interval of the flute ( 200 cents) to that of the bells (207 cents). A paired $t$ statistic of the means of the two scales was not significant at the $35 \%$ level of confidence $(t(10)=-0.94)$. For that matter, a one-way analysis of variance of the means of all three groups of tone data, Ma's (1981) and our data on bells and flute, gave $F(2,36)=.01$; thus we cannot reject the null hypothesis that the means are all equal at about the $30 \%$ level of confidence.

Important similarities between the bell and flute intervals are the perfect physical octave, major third, minor third, and a semitone. The pitch interval between bell tones 3 and 9 and between flute tones 3 and 11 in Tables 2 and 5 is about an octave. The smallest common interval of the scale may be about 90 cents, on the evidence of the interval of bell tones 6 and 7 (87.5 cents) and the interval of flute tones 8 and 9 (93.3 cents). In Table 5, the interval between bell tones 3 and 4 is 318.6 cents and the interval between bell tones 9 and 10 is also 318.8 cents, which interval is equal to the minor third of the 23-tone scale. Flute tones 3 and 5, flute tones 11 and 13 , and bell tones 7 and 9 have intervals of 357.0, 362.9, and 367.6 cents, respectively. These three intervals average 24 cents below the major third of the 23 -tone scale. One other piece of evidence is the interval of 61 cents between flute tones 15 and 16 , which is very close to the smallest interval (66 cents) of the 23-tone scale. Just below we educe on more theoretical grounds that 66 cents is the smallest interval of the bamboo flute scale.

Some errors of intervals are to be expected in manufacturing. The pitches of bells have to be regulated after casting by thinning and soldering (Needham, 1962). Pitches of the bamboo flute are adjusted by boring or cutting in order to modify the shape, edge, and slope of the holes. It is very likely that the ancient Zhou bells have shifted some in pitch because of mechanical or chemical erosion over two and a half centuries. Even so, we can discern from our data some hints about the underlying scale. The scale cannot be 12-tone equal temperament, as Ma (1981) suggested for the 13 Zhou bells, else the intervals would all be 100 cents. The pure major and minor third, and the perfect physical octave of 1200 cents rules out generation of a scale by the cycle of fifths with its octave of 1,224 cents.

There should exist at least one scale lying between equal temperament and just intonation. Several pieces of evidence lead us to believe that the flute, if not also the bell ensemble, is based on the Chinese pure-scale system of 23 notes of unequal interval, which contains several in- 
tervals of 66,90 , and 114 cents and also a major third of 384 cents and a minor third of 318 cents (Pan \& Rao, 1975).

It would be astonishing if bell and flute scales were identical. Even if they were, proving it would not be easy. The bell ensemble may be incomplete, as we have suggested, and almost certainly aging and corrosion have wrought some pitch shifts. And the scale of the ancient bells remains fixed in time at 2,400 B.C., whereas the organic bamboo flute was freer to change. We believe that Zhou bells and bamboo flutes both belong to a pure scale that gives the musician freer modulation than does just intonation. It appears that the bell and flute scales have their origins in a common pure scale, and that the flute scale is based on the 23-tone pure scale of unequal intervals. Our belief is supported by the continuous development of music in Chinese history (Apel, 1972, p. 154) and is consonant with that of Parry and Hubert (1930, p. 20), who said, "Scales are made in the process of endeavoring to make music, and continue to be altered and modified."

We made a crude test of the hypothesis that some one (or more) interval step size, $S$, underlay the flute and bell scales. In particular, we wished to examine $S$ s of 60,66 , 90,100 , and 114 cents. For each interval $I_{j}(j=1,2, \ldots$,

a



b

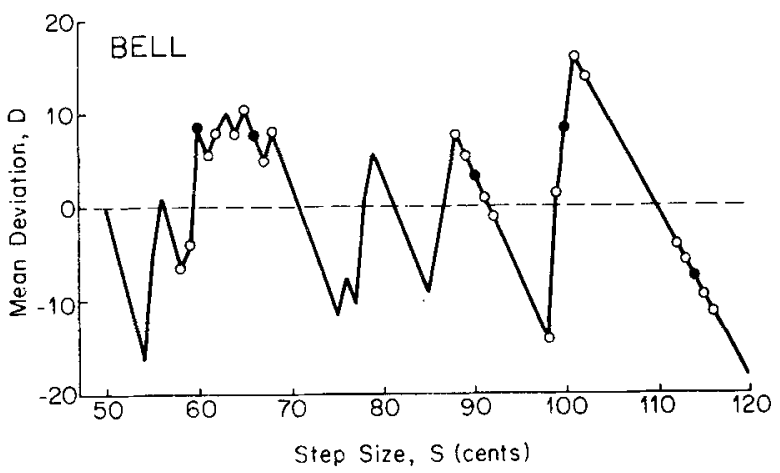

Figure 7. On the ordinate is plotted the minimum deviation $D$, in cents, of the intervals for a given step size, $S$, as a function of $S$ in cents plotted on the abscissa. (a) Flute; (b) bells. See text for definitions. Solid circles show $S$ s of $60,66,90,100$, and 114; open circles show $\pm 2 S s$ from each of these.
Table 6

Mean Deviations $(D)$ and Weighted $R M S$ Deviations $\left(R M S_{w}\right)$ of the Zhou Bell and Flute Intervals From the Nearest Integral Multiple of Various Assumed Basic Step Sizes ( $S$ in Cents)

\begin{tabular}{rllrrr}
\hline$S$ & & \multicolumn{1}{c}{$D$} & \multicolumn{1}{c}{$D / S$} & $R M S_{w}$ \\
\hline 60 & Bell & 8.72 & .15 & 1.16 \\
& Flute & -4.45 & -.07 & .90 \\
66 & Bell & 7.63 & .12 & .88 \\
& Flute & 2.05 & .03 & 1.20 \\
90 & Bell & 3.26 & .04 & .91 \\
& Flute & -4.45 & -.05 & .64 \\
100 & Bell & 8.72 & .09 & 1.00 \\
& Flute & -19.45 & -.19 & 1.04 \\
114 & Bell & -7.65 & -.07 & .88 \\
& Flute & 6.05 & .05 & 1.11 \\
\hline
\end{tabular}

Note:

$$
\begin{aligned}
D & =\frac{1}{11} \sum_{j=1}^{j=11}\left(I_{j}-n S\right), \\
R M S_{w} & =\left[\frac{1}{11} \sum_{j=1}^{j=11}\left(I_{j}-n S\right)^{2}\right]^{1 / 2} / S,
\end{aligned}
$$

where $n$ is the integer that minimizes the deviation $\left(I_{j}-n S\right)$, and $S$ is the step size.

11) and for a fixed $S$ an integer, $n$, was varied until $I_{j}-n S$ was a minimum. For generality, we computed for each $S(S=21,22, \ldots, 120)$ the mean minimum deviation over the 11 intervals; these are plotted in Figure 7 for both flute and bell. Only values of 50 to 120 cents are shown because intervals of less than about 60 cents do not occur in practical scales. There is nothing remarkable about the mean deviations for values of $S$ between 20 and 49.

Table 6 shows the mean deviations for the 5 values of $S=60,66,90,100$, and 114 cents. Because the rootmean square $(R M S)$ values associated with mean deviations increase in direct proportion to $S$, we also report weighted mean deviations and weighted $R M S$ values (Table 6 , Columns 4 and 5). However, we emphasize that the correlation between the values of $S$ and associated mean deviations are not high: $r_{S, D}$ (bell) $=-.1398$ and $r_{s, D}$ (flute) $=-.187$ (with coefficients of determination of .0195 and .0350 ). Neither correlation is significantly different from zero at the $p=.05$ level, by a $t$ test with 120 degrees of freedom.

Taken together with our other data and arguments, the data of Table 6 lead us (1) to reject the hypothesis that 100 cents is an interval in either the bell or the flute scale, since both flute $(-19.45)$ and bell $(8.72)$ deviations are largest for this interval; (2) to consider it very likely that the intervals of $66(2.05), 60(-4.45)$, and $90(-4.45)$ figure in the flute scale, since the deviations are relatively small and would be expected on other grounds; (3) to conclude that the intervals of $60,66,100$, and 114 cents probably do not figure in the bell scale, since the associated mean deviations are all large; (4) to conclude that 90 cents is a basic interval of the bell scale; and (5) to conclude that bell and flute scales have a common interval of 90 cents. 
For completeness, we mention that the same computations on the Zhou bell (physical) intervals of the 13 sui notes (Ma, 1981) yielded the smallest deviation $(-.27)$ for $S=100$ cents and the largest for $S=114$ cents $(-17.00)$ and 66 cents $(-9.36)$. Intermediate values resulted for $S=60$ (4.27) and $S=90$ (4.27). Ma's bell intervals are based on fundamentals found by physical methods. Because only pitch-matching experiments can reveal subjective pitches or intervals of a bell that has complex inharmonic partials, we do not pursue the meaning of the physically measured sui tones or intervals for musical scales.

We conclude from the limited evidence at hand that the underlying musical scales of the 2,400-year-old Zhou ensemble of 13 bells and the modern bamboo flute manufactured today in Weng-Zhou City, China, are very similar, if not the same, and that the 64-bell ensemble shows the same musical scale as that analyzed in a separate paper (Pan \& Rao, 1975). Apparently the strong musical and cultural traditions of China and the biological constancy of the human ear have conspired to maintain a pure-scale system across two and a half millenia.

\section{Consonance of the Tones of the Flute and Zhou Bells}

Over the 13 bell tones, the mean interval between $g u$ and sui is 1.20771 , with a standard deviation of .04246 . This corresponds to a distance of 326.73 cents and a standard deviation of about 61 cents; in the equal-temperament scale, a major third is $\mathbf{4 0 0}$ cents and a minor third is $\mathbf{3 0 0}$ cents, and in the pure-scale system, a major third is $\mathbf{3 8 6}$ cents and minor third is 316 cents.

Plomp (1976) concluded that a listener's ability to identify the individual components of a complex sound is about the same for inharmonic and harmonic partials. The mini- mum frequency separation required for identification is constant at about $60 \mathrm{~Hz}$ for low frequencies (below $400 \mathrm{~Hz}$ ); for middle and higher frequencies the separation is a nearly constant percentage of frequency of $15 \%$ to $20 \%$. This relationship parallels the critical band function, which, roughly, is the minimum frequency separation beyond which a pair of tones are heard as separate and distinct, with no beating, roughness, or noise.

In Table 7, Columns 2 and 3, we give the sui and gu frequencies reported by $\mathrm{Ma}(1981)$ for a particular set of 13 bells. We have computed the ratio of a bell's sui and $g u$ frequencies (Column 4) and the interval in cents (Column 5). The mean frequency ratio is about 1.20771 (327 cents), with a standard deviation of 0.04246 (61 cents). Thus the mean sui-gu interval lies about .44 standard deviations above a minor third (a ratio of 1.1891) and 1.23 standard deviations below a major third (a ratio of 1.2599).

Based on pure-tone studies (Plomp \& Levelt, 1965), the graph of Figure 8 plots normalized judged consonance on a scale of 0 to 1 (ordinate) against the ratio of intervals to the critical bandwidth of hearing (abscissa). Thus the sui-gu interval of Bell 11 is $395 \mathrm{~Hz}$ and the critical bandwidth of the interval midpoint (ca. $1847 \mathrm{~Hz}$ ) is $328 \mathrm{~Hz}$. Hence the ratio $(395 / 328)=1.20$ corresponds to a consonance of 1.0. This general theoretical notion is based on pure-tone intervals and has considerable appeal as a descriptive device. (For some cogent objections on musical grounds, see Davies, 1978.)

From Figure 8 we see that all but two of the sui-gu intervals of the Zhou bells studied by Ma (1981) have consonance values near 1.0 and lie near or above a minor third (see Figure 9). Two bells, Bells 6 and 10, have consonance values of 0.60 and intervals of about a whole tone (Figure 9). Statistically, the sui-gu intervals of Bells 6

Table 7

Physical Frequencies of the Sui and Gu Notes of a Set of 13 Zhou Bells

\begin{tabular}{ccccccc}
\hline Bell* & Sui $(\mathrm{Hz}) \dagger$ & $G u(\mathbf{H z})$ & $\begin{array}{c}\text { Ratio } \\
(\text { Gu/Sui) }\end{array}$ & $\begin{array}{c}\text { Interval } \\
\text { (Cents) }\end{array}$ & $\begin{array}{c}\text { Critical } \\
\text { Bandwidth } \ddagger\end{array}$ & $\begin{array}{c}\text { Interval (Hz)/ } \\
\text { Critical Bandwidth }\end{array}$ \\
\hline 1 & 508.5 & 618.9 & 1.21711 & 340 & 99 & 1.11 \\
2 & 542.3 & 673.8 & 1.24249 & 376 & 106 & 1.25 \\
3 & 608.0 & 739.6 & 1.21645 & 339 & 118 & 1.12 \\
4 & 729.9 & 881.7 & 1.20930 & 329 & 141 & 1.09 \\
5 & 812.6 & 978.4 & 1.20404 & 321 & 157 & 1.06 \\
6 & 911.1 & 1059.7 & 1.16310 & 262 & 168 & .60 \\
7 & 982.5 & 1163.4 & 1.18412 & 293 & 188 & .96 \\
8 & 1092.0 & 1331.3 & 1.21914 & 343 & 212 & 1.13 \\
9 & 1213.5 & 1542.6 & 1.27120 & 415 & 241 & 1.37 \\
10 & 1483.6 & 1645.7 & 1.10926 & 180 & 274 & .59 \\
11 & 1649.6 & 2044.1 & 1.23915 & 371 & 328 & 1.20 \\
12 & 1819.1 & 2273.8 & 1.24996 & 386 & 358 & 1.17 \\
13 & 2363.3 & 2776.8 & 1.17497 & 279 & 451 & .92 \\
& Mean & & 1.20771 & 327 & & \\
& SD & & .04246 & 61 & & \\
\hline
\end{tabular}

Note-The mean value of the sui-gu interval, 1.20771, should be compared with the equaltemperament values of a minor third (1.189207), a major third (1.259921), and a whole tone (1.122462), and with a just-intonation major third $(1.250000)$ and minor third (1.200000). See also Figure 8. *Frequency data from holographic measurements reported by Ma (1981). $\nmid$ Pearson product-moment correlation coefficient $r_{\text {sut-su }}=0.97$. $\ddagger$ For the center frequencies of the sui-gu intervals. 


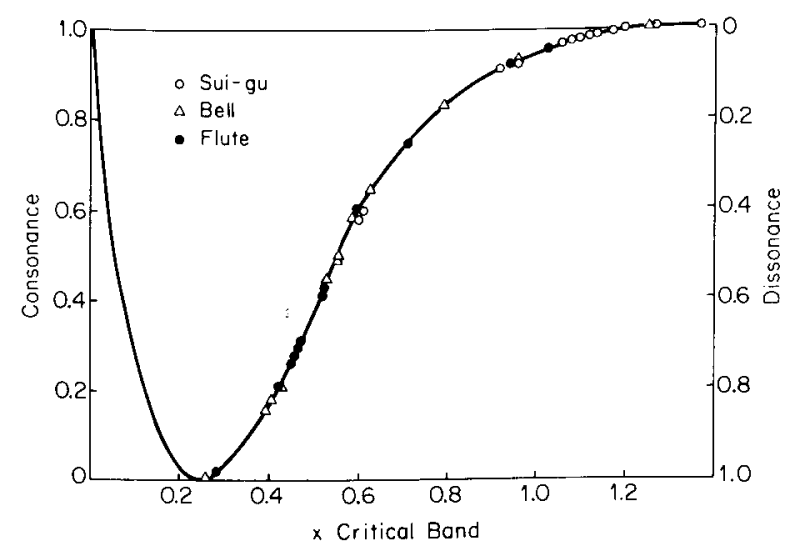

Figure 8. Consonance (or dissonance) of sui-gu, bell, and flute tones are plotted on the ordinate as a function of the ratio of a given interval to its appropriate critical bandwidth. For example, the flute tone (filled circle) at a consonance of 0.75 has a ratio to the bandwidth of about 0.7 .

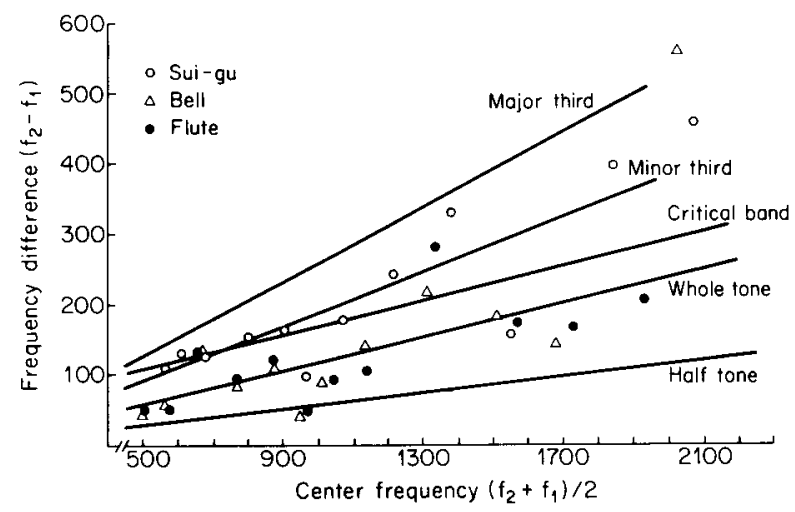

Figure 9. Intervals of various tones plotted as frequency differences ( $(2-f 1)$, in hertz, as a function of the center frequency $[(\boldsymbol{f}+\mathbf{f 1}) / 2]$ between tones (abscissa). Sui-gu tones are shown as open circles, Zhou bell tones as open triangles, and flute tones as filled circles. Some important musical intervals, and the critical bandwidth as well, are shown as straight lines. For example, the bell interval whose center frequency is about $1500 \mathrm{~Hz}$ lies on the whole-tone line of the equal-temperament scale.

and 10 are 1 and 2.3 standard deviations below the mean sui-gu interval of 1.20771 (Table 7). Relative to the highly consonant intervals of octave and unison, the third is generally rated mildly consonant. We infer from the mean of about 1.21 that the ancient bell craftsmen were seeking an interval of about a musical third. It is likely that some 2,400 years of oxidation has lowered the perceived pitch, as we would expect from thinning of the metal. ${ }^{3}$ It is not clear how, or whether, the interval would change with aging of the bells. The smaller intervals of Bells 6 and 10 were intended by the makers or were errors made in casting and were probably not caused by secular drift.

Table 8 shows the intervals in hertz for the 13 tones of the Zhou bells as measured by us, and the correspond- ing flute tones. The ratios formed by these intervals divided by the appropriate critical bandwidth of hearing are shown in the last two columns of Table 8 and are also plotted in Figure 8. A few of the bell and flute tones are high in consonance, but most are low, which is not unexpected for adjacent tones of a scale (the $g u$-sui ratios are of two modes within a bell). Note that the smallest interval found in the Zhou bells and in the flute (about 90 cents) is maximally dissonant, just as the interval of 100 cents is the smallest and most dissonant interval of the equal-temperament scale.

Figure 9 sets the Zhou bells and flute in the context of the equal-temperament scale. Most of the bell and flute intervals lie in the space between a half tone (100 cents) and a whole tone ( 200 cents). Two bell intervals and two flute intervals are outside a critical bandwidth and near a minor third ( 300 cents). The extreme bell interval, about a major third, is evidence that two or more bells are mising and probably lie between Bells $12(1745 \mathrm{~Hz})$ and 13 $(2307 \mathrm{~Hz})$. We have discussed above the relationship of the underlying musical scales of the Zhou bells and the flute.

\section{A Note on Musical Scales}

History tells us that attempts were made very early to modify rational scales, such as the Pythagorean scale, so

Table 8

Data From Subjective Pitch Matches on Zhou Bells and Bamboo Flute

\begin{tabular}{|c|c|c|c|c|c|c|}
\hline \multicolumn{2}{|c|}{ Number } & \multicolumn{2}{|c|}{ Interval (Hz) } & \multirow{2}{*}{$\begin{array}{c}\text { Critical Band- } \\
\text { width }(\mathrm{CB}, \text { in } \mathrm{Hz})\end{array}$} & \multicolumn{2}{|c|}{ Interval/CB } \\
\hline Bell & Flute & Bell & Flute & & Bell & Flute \\
\hline 1 & 1 & & & & & \\
\hline 2 & $2:$ & 44 & 45 & 106 & .42 & .42 \\
\hline & $:$ & 62 & 61 & 118 & .53 & .52 \\
\hline 3 & 3 & & & & & \\
\hline 4 & $5:$ & 135 & 134 & 141 & .96 & .95 \\
\hline & : & 86 & 94 & 157 & .55 & .60 \\
\hline 5 & 6 & 108 & 120 & 168 & 63 & 71 \\
\hline 6 & 8 & 100 & 120 & 100 & .00 & .11 \\
\hline & : & 48 & 52 & 188 & .26 & .28 \\
\hline 7 & 9 & & & & & \\
\hline & : & 87 & 96 & 212 & .41 & .45 \\
\hline 8 & 10 & & & & & \\
\hline & $:$ & 142 & 112 & 241 & .59 & .46 \\
\hline 9 & 11 & & & & & \\
\hline 10 & $13^{:}$ & 220 & 283 & 274 & .80 & 1.03 \\
\hline & : & 179 & 171 & 328 & .55 & .52 \\
\hline 11 & 14 & & & & & \\
\hline & : & 143 & 165 & 358 & .40 & .46 \\
\hline 12 & 15 & & & & & \\
\hline 13 & : & 562 & 211 & 451 & 1.25 & .47 \\
\hline
\end{tabular}

Note-The critical bandwidth is for the mean frequency, $\left(f_{2}+f_{1}\right) / 2$. The values of Columns 6 and 7 are also plotted in Figure 8 in a way that indicates the dissonance or consonance of bell and flute intervals relative to the (theoretical) consonance of pure-tone intervals (see Plomp, 1976). 
as to gain flexibility of intonation and modal changes. For Aristoxemus (ca. A.D. 320), a pupil of Aristotle, subjective judgment was the basis for a theoretical scale that used 2 fractional tones as elements for generating musical scales in different modes. Each of the fractional tones, a quarter and a third tone, was smaller than a Pythagorean hemitone. The resulting scale was an early attempt to temper the musically intractable rational scales.

Al-Farabi (ca. A.D. 870-950), a Muslim philosopher and musician, recognized and used as consonances the major third (5:4) and minor third $(6: 5)$ that were dissonances in the Pythagorean scale. Of very great significance was Al-Farabi's introduction of organum, or doubling, with consonant intervals of the third, fourth, or fifth. "AlFarabi's acceptance and use of these intervals constitute circumstantial evidence that at least some modification of the Pythagorean scale had already attained a degree of currency by the tenth century' (Hunt, 1978, p. 51).

According to Hunt (1978), Bartolomeo Ramos de Pareia (A.D. 1482) grasped that an equal temperament was the solution to the problems of modality and musical scale, but Zarolina (A.D. 1588) is usually credited with this proposal. Needham (1962) thought it probable that the $2^{1 / 2}$ solution was discovered in China by Chu Tsai-Yu (A.D. 1584) whence the principle was transmitted to the West. However, the transmission has not yet been proved. McClain (1985) believed that the Zhou carillon is a 5octave chromatic chime-set, with most of its bells tuned to the "philosophical pitch standard" (middle C = $256 \mathrm{~Hz}$ ). He argued from the evidence of some 2,800 inscriptions on the bells that in 500 B.C. the tone systems of China and Greece shared extensive structural similarities.

\section{Psychoacoustics of Complex Tones and Strike Notes}

The perception of complex tones has been at the heart of a paradox in the assignment of musical pitch of bells. Lord Rayleigh $(1890,1894)$ made a systematic study of a ring of bells at Terling in 1879 . He found, for one bell, that the approximate tone sequence of D1b, A1b, D2, G2, and B2 had frequency ratios of about 1.0, 1.5, 2.0, 2.7, and 3.3., respectively. The strike note (the heard musical pitch, in this case B1) was an octave below the fifth partial. This curious relation between the strike note and the fifth was confirmed in seven other bells. Using Helmholtz resonators, as did Lord Rayleigh, to identify partials, Jones (1920) found pitches by sonometer frequency matches of the tones of Carlile Chime at Smith College in Northampton, Massachusetts. The strike note could not be picked up by a resonator, could not be elicited by a resonator, and did not beat with a note of nearly the same pitch. In this study and in a later study (Jones, 1928) using a microphone, amplifier, and oscillograph, Jones found that no partial tone had the same pitch as the strike note, but that the fifth partial was an octave above it. He con- cluded that a strike note is not a difference tone, and that the strike note of the Carlile Chime did not arise from compressional waves in the bronze.

The pitch of the striking note seems to be determined by the fifth partial, the octave in which it lies being, however, generally misjudged. A possible reason for this general failure in correct estimation of the octave is found in the rates at which the different partials reach their maximum intensities. (Jones, 1920, p. 247)

In psychoacoustics, it was well known that a complex tone could be assigned a pitch even when the corresponding fundamental component was absent. Schouten (1938) explained this problem of the missing fundamental by his periodicity pitch theory. The assigned pitch ("residue" pitch) was, he said, derived from the waveform periodicity of the unresolved higher components. As early as 1939, Schouten had explained the strike note of bells as a residue (Schouten \& 't Hart, 1965/1983).

There is no general way of calculating subjective pitch from a sound having inharmonic partials, such as the sound of a bell, although there is some rational basis for predicting the pitch of a complex tone. A recent survey of the pitch of complex tones was given by Plomp (1975) (much of the work reported is by the Dutch). As a neutral term for residue or periodicity pitch, Plomp suggested the term low pitch. The low pitch of a complex tone with a fundamental $f_{0}$ up to $200 \mathrm{~Hz}$ depends on the fourth and fifth harmonics. But the harmonic number decreases as $\mathrm{f}_{\mathrm{o}}$ increases, so that the harmonics lie in the "dominant" region ( 500 to $2000 \mathrm{~Hz}$ ). The low pitch does not depend upon the phase relations of the harmonics. Plomp's general conclusion was that the low pitch is extracted from those lower components resolved by the ear and not from the unresolved higher harmonics. This is consistent with de Boer's (1956) model, which assumes that the ear is a pitch extractor that searches for the harmonic complex of the inharmonic complex.

The models put forth to account for the perception of the residue and other effects of complex tones are mainly of two types. Pattern recognition models (e.g., Terhardt, 1974) assume that the pitch of a complex tone depends on neural effects of the partials. Temporal models (Schouten, 1940, 1970) assume that pitch depends on time interval measurement. According to Moore (1982), these models do not account for all the data; hence he proposed one that accounts for the data qualitatively by combining the features of both models.

Several recent papers are germane here. Moore, Glasberg, and Peters $(1985,1986)$ reported that a harmonic relative to its adjacent harmonics can have a significant effect on its dominance and that the pitches of complex or inharmonic tones may differ significantly among individuals. The results of Moore, Peters, and Glasberg (1985) suggest that inharmonic low partials are detected by their salience (they "stand out'), whereas higher par- 
tials are detected as beats or roughness. A partial that is so far mistuned as to make it audible as a separate tone may still contribute significantly to the pitch of the complex as a whole. This last result helps explain why bells retain a musical quality in spite of the presence in their tones of mixtures of series of inharmonic partials.

Our spectral and perceptual analyses suggest that there may be an important difference between the Zhou bells and the western bells studied by Lord Rayleigh (1894), Jones $(1920,1928)$, Schouten $(1938,1965)$, and many others. Although the strike note of the western bells often is absent from the spectrum, in none of the 13 Zhou bells is the strike note absent from the physical spectrum, in the sense that the assigned pitch for a given bell lies very near the frequency of a partial in the spectrum. Bell tone 8 may be an exception.

Using the average pitch matches of the 5 listeners, the mean deviation of mean subjective pitch from the nominal frequency over all 13 bells was found to be 6.69 cents, with a standard deviation of 15.21 cents. Bell tone 8 has the largest difference, about $2 \%(1098-1075=23 \mathrm{~Hz})$, which is 37 cents. In fact, the mean differences are close to the threshold for pitch discrimination, which ranges from about $1 \%$ at $500 \mathrm{~Hz}$ to $.5 \%$ at $1000 \mathrm{~Hz}$ (Shower \& Biddulph, 1931). Thus the discriminability is about 17 cents at $500 \mathrm{~Hz}$ and about 9 cents at $1000 \mathrm{~Hz}$. In musical contexts pitch discrimination is less good. We conclude that the theory of residue pitch generally need not be invoked to account for the pitch matches made to the Zhou bells.

In the absence of a model of the Zhou bells or a set of measurements showing the relation between mode and spectrum, and not knowing the strike notes of all the Zhou bells, it is not possible to say whether Zhou bells have strike notes that are not present in the spectrum. The 13 bells studied here appear to have harmonics that lie in the dominant region of 500 to $2000 \mathrm{~Hz}$; therefore, the low tone lies in the spectrum. No doubt a major difference between these Chinese bells and western bells is in the shape. Western bells are circularly symmetric, have a thick sound bow, and are tuned by empirically based models so as to generate a standard set of eigenfrequencies. The shape of a Zhou bell is nearly that of a truncated elliptical cone shell with concave edges at the mouth. The largest, Bell 1 , is $30.12 \mathrm{~cm}$ high and weighs $4.4 \mathrm{~kg}$ (Maa \& Chen, 1986), with a strike tone of about B4 (494 Hz). Western (church) bells are generally much more massive. For example, one of the bells studied by Lord Rayleigh (1894) weighed about $4 \mathrm{cwt}$ (about $200 \mathrm{~kg}$ ) and had a strike note of d" (about D5, or $587.33 \mathrm{~Hz}$ ).

It appears, however, that because Western church bells are large and heavy they produce great sound power that decays slowly, a fact related to the thick waist and sound bow. The 13 Chinese bells are like western handbells, which have a thin waist and no sound bow and are rarely tuned to more than 2 partials (Rossing \& Sathoff, 1980). But whether church bell, carillon, chime bell, or tubular chime, the low pitch of the sound may fail to appear as a spectral component. Indeed, Schouten related (Schouten \& 't Hart, 1965/1983) that in 1939 he was consulted on the false tuning of an amplified Westminster chime made up of four steel springs. The strike note was not in the spectrum but was the residue of the $3 \mathrm{rd}, 4$ th, and 5 th eigenfrequencies and lay one octave below the 3rd partial.

\section{REFERENCES}

APEL, W. (1972). Harvard dictionary of music. Cambridge, MA: Harvard University Press.

DAviES, J. B. (1978). The psychology of music. Stanford, CA: Stanford University Press.

DE BOER, E. (1956). On the "residue" in hearing. Doctoral dissertation, University of Amsterdam, Amsterdam.

Hunt, F. V. (1978). Origins in acoustics. New Haven, CT: Yale University Press.

Jones, A. T. (1920). The tones from bells. Physical Review, 16, 247-259.

Jones, A. T. (1928). The vibration of bells. Physical Review, 31, 1092-1102.

Lord Rayleigh (J. W. Strutt). (1890). On bells. Philosophical Magazine, 29, 1-17.

LoRd Rayleigh (J. W. STRUTt). (1894). The theory of sound. London: Macmillan.

Ma Chengyuan (1981). Two-pitch bronze bells of the Shang-Zhou period. Musical Studies, 4, 131-146.

MaA Dah-You \& Chen Tong (1986). Chinese musical instruments of the pre-Christian era. Proceedings of the 12th Intemational Congress on Acoustics, III, K6-1, Toronto, Canada.

MCCLAIN, E. G. (1985). The bronze chime bells of the Marquis of Zeng: Babylonian biophysics in ancient China. Journal of Social \& Biological Structure, 8, 147-173.

Moore, B. C. J. (1982). An introduction to the psychology of hearing. New York: Academic Press.

Moore, B. C. J., Glasberg, B. R., Peters, R. W. (1985). Relative dominance of individual partials in determining the pitch of complex tones. Journal of the Acoustical Society of America, 77, 1853-1860.

Moore, B. C. J., Glasberg, B. R., \& Peters, R. W. (1986). Thresholds for hearing mistuned partials as separate tones in harmonic complexes. Journal of the Acoustical Society of America, 80, 479-483.

Moore, B. C. J., Peters, R. W., \& Glasberg, B. R. (1985). Thresholds for the detection of inharmonicity in complex tones. Journal of the Acoustical Society of America, 77, 1861-1867.

Needham, J. (1962). Science and civilisation in China (Vol. 4, Part 1). Cambridge, England: Cambridge University Press.

PAN HAi-Si \& Rao YU-AN. (1975). An exploration of the pure tone system of Chinese music. Unpublished manuscript.

PARry, C., \& HUBERT, H. (1930). The evolution of the art of music. New York: Appleton-Century.

Plomp, R. (1976). Aspects of tone sensation. New York: Academic Press.

Plomp, R., \& Levelt, W. J. M. (1965). Tonal consonance and critical bandwidth. Journal of the Acoustical Society of America, 38, 548-560.

Rossing, T. D., \& SATHOFF, H. J. (1980). Modes of vibration and sound radiation from tuned handbells. Journal of the Acoustical Society of America, 68, 1600-1607.

Schouten, J. F. (1938). The perception of subjective tones. Proceedings of the Koninklijke Akademie van Weterschappen, 41, 1086-1093.

SCHOUTEN, J. F. (1940). The residue and the mechanism of hearing. Proceedings of the Koninklijke Akademie van Weterschappen, 43, 991-999.

Schouten, J. F. (1970). The residue residue revisited. In R. Plomp \& G. F. Smoorenburg (Eds.), Frequency analysis and periodicity detection in hearing (pp. 000-000). Leiden, The Netherlands: Sijthoff.

SCHOUTEN, J. F. \& 'T HART, J. (1983). The strike note of bells. In T. D. Rossing (Ed. and Trans.), Acoustics of bells (pp. 245-255). New York: 
Van Nostrand Reinhold. (Reprinted from Netherlands Acoustical Society Publications, 1965, 7, 8-19)

SHOWER, E. G., \& BiDduLPH, R. (1931). Differential sensitivity of the ear. Journal of the Acoustical Society of America, 2, 275-287.

TAN Weisi \& GuAngsheng Feng (1981). Approaches to the musical properties of the small bells in the uppermost row of the bell-chime. Musical Studies (Yinyue Yanjiu, in Chinese), 4, 79-87.

Terhardt, E. (1974). Pitch, consonance, and harmony. Joumal of the Acoustical Society of America, 55, 1061-1069.

Wang XIANg (1981). An exploration of the temperament of the bellchime excavated from Zen Houyi's tomb. Musical Studies (Yinyue Janjiu, in Chinese), 4, 68-78.

\section{NOTES}

1. The English spelling of transliterated Chinese forms agrees with the official convention of China.

2. We follow Needham's (1962) dating of Chinese dynasties.

3. Removing metal will generally lower the frequencies of the modes, since the bending energy of a plate is proportional to the cube of its thickness, whereas the mass is linear with thickness. Lord Rayleigh (1890) remarked, "If there is anything well established in theoretical acoustics it is that the frequencies of vibration of similar bodies formed of similar material are inversely as the linear dimensions-a law which extends to all the possible modes of vibration"' (p. 12). 